\title{
Genetic analysis of ALS cases in the isolated island population of Malta
}

\author{
Rebecca Borg ${ }^{1,2}$ - Maia Farrugia Wismayer ${ }^{1,2} \cdot$ Karl Bonavia' $^{1}$ Andrew Farrugia Wismayer ${ }^{1} \cdot$ Malcolm Vella $^{3}$. \\ Joke J. F. A. van Vugt ${ }^{4} \cdot$ Brendan J. Kenna $^{4} \cdot$ Kevin P. Kenna ${ }^{4}$. Neville Vassallo ${ }^{1,2} \cdot$ Jan H. Veldink $\mathbb{B}^{4}$. \\ Ruben J. Cauchi $\mathbb{1}^{1,2}$
}

Received: 6 May 2020 / Revised: 16 October 2020 / Accepted: 23 October 2020 / Published online: 7 January 2021

(c) The Author(s) 2020. This article is published with open access

\begin{abstract}
Genetic isolates are compelling tools for mapping genes of inherited disorders. The archipelago of Malta, a sovereign microstate in the south of Europe is home to a geographically and culturally isolated population. Here, we investigate the epidemiology and genetic profile of Maltese patients with amyotrophic lateral sclerosis (ALS), identified throughout a 2-year window. Cases were largely male $(66.7 \%)$ with a predominant spinal onset of symptoms $(70.8 \%)$. Disease onset occurred around mid-age (median age: 64 years, men; 59.5 years, female); $12.5 \%$ had familial ALS (fALS). Annual incidence rate was 2.48 (95\% CI 1.59-3.68) per 100,000 person-years. Male-to-female incidence ratio was 1.93:1. Prevalence was 3.44 (95\% CI 2.01-5.52) cases per 100,000 inhabitants on $31^{\text {st }}$ December 2018. Whole-genome sequencing allowed us to determine rare DNA variants that change the protein-coding sequence of ALS-associated genes. Interestingly, the Maltese ALS patient cohort was found to be negative for deleterious variants in C9orf72, SOD1, TARDBP or FUS genes, which are the most commonly mutated ALS genes globally. Nonetheless, ALS-associated repeat expansions were identified in ATXN2 and NIPA1. Variants predicted to be damaging were also detected in ALS2, DAO, DCTN1, ERBB4, SETX, SCFD1 and $S P G 11$. A total of $40 \%$ of patients with sporadic ALS had a rare and deleterious variant or repeat expansion in an ALSassociated gene, whilst the genetic cause of two thirds of fALS cases could not be pinpointed to known ALS genes or risk loci. This warrants further studies to elucidate novel genes that cause ALS in this unique population isolate.
\end{abstract}

\section{Introduction}

Amyotrophic lateral sclerosis (ALS) is an adult-onset, rapidly progressing, neurodegenerative disease. Onset is typically accompanied by clinical signs of upper and/or

Supplementary information The online version of this article (https:// doi.org/10.1038/s41431-020-00767-9) contains supplementary material, which is available to authorised users.

Ruben J. Cauchi

ruben.cauchi@um.edu.mt

1 Centre for Molecular Medicine and Biobanking, Biomedical Sciences Building, University of Malta, Msida, Malta

2 Department of Physiology and Biochemistry, Faculty of Medicine and Surgery, University of Malta, Msida, Malta

3 Department of Neuroscience, Mater Dei Hospital, Msida, Malta

4 Department of Neurology, Brain Center Rudolf Magnus, University Medical Center Utrecht, Utrecht, The Netherlands lower motor neuron degeneration and patients usually present with weakness in the bulbar muscles, only the limbs, or both regions simultaneously. About $15-20 \%$ of persons with ALS experience progressive cognitive decline, leading ultimately to dementia. The condition known as frontotemporal dementia results from the degeneration of the frontal and temporal lobes [1,2]. The incidence of ALS in European populations is two to three cases per year per 100,000 , whereas prevalence can reach 10/100,000 [3]. ALS is classified as familial (fALS) in the presence of a clear family history of the disease and sporadic (sALS) when this is absent. The rate of fALS among prospective population-based registries is about 5\% [4]. Nonetheless, studies on twins and European case-control cohorts have found that heritability of ALS approximates $40 \%$ [5-7]. To date, variants in any of more than 40 genes have been reported to cause monogenic fALS with more than half of the cases explained by highly penetrant causal variants residing in C9orf72 (23\%), SOD1 (19\%), TARDBP (3\%) or FUS (3\%) [8]. Variants in these genes [8-10] and genetic 
risk loci that include ATXN2 [11], UNC13A [12], SARM1 [13], C21orf2, SCFD1 and MOBP [13] have also been exposed in sALS cases. Genetic variants are estimated to contribute to between 14 and $17 \%$ of European sALS patients or those with a European ancestry $[9,10]$. All this underscores the substantial contribution of genetic factors to ALS disease aetiology.

Genetic discoveries often lead to novel insights into the molecular mechanisms of ALS. For instance, clustering genes according to their known physiological functions identified ribostasis, proteostasis and cytoskeletal dynamics as key cellular pathways involved in ALS pathogenesis [14]. Importantly, discovery of genes is leading to the development of genotype-specific treatments [15]. Additional genetic factors remain to be found for ALS. The use of geographically and/or culturally isolated populations for mapping novel ALS genes is a strategy that remains relatively unexploited despite benefits that include founder effects, reduced genetic diversity and minimal environmental heterogeneity [16]. This spurred us to study the native population of Malta, a sovereign microstate in the middle of the Mediterranean Sea. Consisting of an archipelago of three inhabited islands (total area $316 \mathrm{~km}^{2}$ ), Malta's population presently numbers about 514,564, based on Malta's National Statistics Office (NSO) data in 2019. Population seeding events occurred more than 7000 years ago by settlers coming from neighbouring Sicily and based on mitochondrial DNA, Y-chromosome and autosomal DNA marker analyses, influences by colonisers in the centuries that followed were minimal [17-19]. The Maltese are the only European population that speak a Semitic language, further underscoring their relative isolation from other communities inhabiting Europe. Previous successes in gene mapping of rare diseases in the population of Malta are encouraging [20, 21]. Here, we first investigate the incidence and prevalence of ALS in the Maltese islands, in a 2year period. Second, we perform an initial genetic survey by reporting on rare variants in protein-coding regions and consensus splice sites of all presently known monogenic ALS genes and genetic risk loci in Maltese ALS patients compared to matched controls.

\section{Materials and methods}

\section{Participants}

Participant surveillance and recruitment occurred throughout a 2-year window, from 2017 through 2018. Patients diagnosed with probable or definite ALS, referred by either the national Motor Neuron Disease association, consultant neurologists, general practitioners and neurophysiology units were invited to participate in our study. Alternatively, patients or their relatives made direct contact with our laboratory expressing willingness to participate in the study. Patient participants met the revised El Escorial criteria for ALS [22, 23]. Patients with fALS were identified as having a self-reported family history of ALS, or probable ALS, defined as the presence of at least one first-degree relative. In total, 24 patients were enrolled in this study. Blood sampling was excluded for one sALS case in view of the patient's deteriorating condition. Affected family members for all fALS cases were deceased precluding us from sampling them. Controls, which were ascertained in a roughly 2:1 case-control ratio, matched patients for age, sex and geographical region. Ethical approval for the collection of samples, study design and the creation of the Malta ALS/ MND Register and Biobank was given by the Research Ethics Committee of the University of Malta. Written informed consent to participate was sought from all patients and/or family members as well as controls.

\section{Phenotypic information}

Phenotypic information was gathered via a detailed questionnaire in addition to a clinical examination. Each sample is therefore accompanied by a core dataset that includes age, sex, occupation, site of onset, date of disease onset, family history, ALS Functional Rating Scale-revised (ALSFRS-R) score, muscle tone for both upper and lower limbs, muscle power graded according to the MRC scale, and status of reflexes. Information on possible environmental risk factors including physical activity, cigarette smoking and alcohol consumption was also gathered. A biochemical assay to test creatine kinase $(\mathrm{CK})$ levels at recruitment was also utilised.

\section{Incidence and prevalence calculations}

The denominator for the calculation of the incident rate was the sum of total population of Malta in 2017 and 2018. During the study period, the population of Malta increased from 475,701 to 493,559 . Separate incident rates for males and females as well as specific age groups were also calculated. Population numbers were derived from NSO data. The prevalence rate was estimated on $31^{\text {st }}$ December 2018. Confidence limits for incidence were calculated assuming a Poisson distribution.

\section{Whole-genome sequencing}

Extraction of DNA occurred from whole EDTA-containing venous blood samples using the QIAamp DNA Mini QIAcube Kit and DNA integrity was measured using the Quantus fluorometer. DNA was whole-genome sequenced by the BGISEQ-500 platform (BGI, Hong Kong, China) to generate $100 \mathrm{bp}$ paired-end reads with an average depth of $30 \times$. Reads 
were aligned to the GRCh37 (HG19) reference genome using Burrows-Wheeler Aligner software. Single nucleotide variant (SNV) and small insertion and deletion (indel) calling and quality filtering were performed using the Genome Analysis Toolkit (GATK). The ExpansionHunter tool was used to analyse repeat sizes of ATXN2 (NM_002973.3: c.496_498CAG), C9orf72 (NM_001256054.2:c.-45 +163GGGGCC) and NIPA1 (NM_144599.4:c.24_26GGC) [24]. In order to estimate the genetic ancestry in relation to reference maps of diverse populations, principal-component analysis (PCA) was performed on LASER with results plotted using the LASER Server plot facility (https://laser.sph.umich. edu/). HomozygosityMapper (www.homozygositymapper. org) [25] was used to map runs of homozygosity (ROHs).

\section{Variant analysis}

We searched for and analysed protein-coding and splice-site altering variants and indels in 58 established ALS causative or risk genes (Table 1). We restricted analyses to variants with European minor allele frequency (MAF) $\leq 0.01$, which corresponds roughly to the European frequency of the recently discovered ALS risk NM_004984.2:c.2957C>T; p.(Pro986Leu) allele in the KIF5A gene [26]. Where available, variants were then annotated with information from the dbSNP database including European-specific MAF estimates from the Genome Aggregation Database (gnomAD). Allele frequencies for ALS cases and controls within the Project MinE dataset were extracted from the Project MinE databrowser [27]. To determine variant pathogenicity, MetaSVM and MetaLR, two ensemble-based prediction methods integrating multiple scoring systems, were used in view of their superior predictive ability relative to other methods [28]. Variants were considered as damaging if outcomes of both methods concurred. Indels and splice-site acceptor/donor variants were automatically classified as deleterious. Variants and the associated phenotypes have been submitted to the ClinVar database (https://www.ncbi.nlm.nih.gov/clinvar/) with accession numbers SCV001426191, SCV001426206-SCV001426210, SCV001426221-SCV001426223 and SCV001437161SCV001437192. New variants detected in the Maltese casecontrol cohort were submitted to the dbSNP database (https://www.ncbi.nlm.nih.gov/snp/) with the submission SNP IDs of ss2137544106, ss3986090479, ss3986090480, and ss3986090481.

\section{Statistics}

Comparisons between means were made with the unpaired, two-tailed Student $t$ test, whereas comparison between categorical variables was made with $\chi^{2}$ test. A $p$ value $<0.05$ was considered significant. Data were processed with GraphPad Prism v8.4.0 software.

\section{Results}

\section{Baseline characteristics}

The key characteristics of patients and controls are detailed in Table 2. ALS cases were largely male with a predominant spinal onset of symptoms. Bulbar onset ALS had a slightly higher occurrence in females (57.2\%). Disease onset occurred around mid-age with median age at onset being lower in females (59.5 years) compared to males (64 years). Only one male and female patient was under 45 years old $(8.3 \%)$. Early ALS ( $\leq 55$ years) was more frequently spinal at onset (spinal/bulbar ratio $=9: 1)$. A family history of ALS was recorded for a minority of cases (Table 2). However, considering their familial aggregation with ALS [29-31], the inclusion of both a family history of dementia and neuropsychiatric endophenotypes-like schizophrenia or psychosis, increases the proportion of fALS to $37.5 \%(9 / 24$ patients). The mean duration of the illness was $44.5 \pm 28.3$ SD months, with males having a faster progression compared to females $(29.6 \pm 8.8 \mathrm{SD}$ months vs. $66.8 \pm 33.4 \mathrm{SD}$ months, $p=0.0065$ ). Site of disease onset did not influence disease duration (spinal onset $=43.5 \pm 32.4 \mathrm{SD}$ months, bulbar onset $=43.7 \pm 19.8 \mathrm{SD}$ months, $p=\mathrm{NS}$ ).

One-third of the ALS patients recruited had a history of heavy smoking and more than half reported an occupation associated with strenuous activity, both of which have been implicated as environmental risk factors for ALS [32, 33]. Alcohol abuse in the patient cohort was minimal. In view that a number of years have elapsed from onset up to recruitment, the levels of $\mathrm{CK}$ in the patient cohort were on average only slightly above the normal range. The mean ALSFRS-R score in ALS recruits was nearly half that recorded for the control subjects with the score in the latter nearing 48, the maximum expected in healthy individuals. The distribution of cases and controls throughout the Maltese islands are displayed in Fig. 1. A higher population density in the southeast of mainland Malta, most probably explains the increase in the number of cases in this geographic region relative to other regions.

\section{Incidence and prevalence rates}

The annual incidence rate for ALS in the 2017-2018 period was 2.48/100,000 person-years (95\% CI 1.59-3.68). The male-to-female incidence ratio was $1.93: 1$. Hence, incidence rate was higher for men $(3.25,95 \%$ CI 1.86-5.28) than for women $(1.68,95 \%$ CI $0.72-3.31)$, and this trend occurred across all age groups after 49 years (Fig. 2). For both men and women, the incidence increased with age but declined after age 79 . Peaks occurred in the 50 to 59 age group among men and in the 70 to 79 age group among women. A total of 17 patients $($ male $=12$, female $=5$ ) were 
Table 1 ALS-associated genes investigated in this study, and their basic characteristics.

\begin{tabular}{|c|c|c|c|c|}
\hline Gene & Chromosome locus & Genetic effect & $\begin{array}{l}\text { Transcript } \\
\text { length (kbp) }\end{array}$ & Putative pathway/function \\
\hline$A L S 2$ & $2 \mathrm{q} 33.1$ & $\mathrm{AR}$ & 6.68 & Vesicular trafficking \\
\hline$A N G$ & $14 \mathrm{q} 11.2$ & $\mathrm{AD}$ & 1.22 & Angiogenesis \\
\hline ANXA11 & $10 \mathrm{q} 22.3$ & $\mathrm{AD}$ & 6.97 & Proteostasis \\
\hline ATXN2 & $12 \mathrm{q} 24.12$ & $\mathrm{AD}, \mathrm{RF}$ & 4.7 & Ribostasis; endocytosis \\
\hline C21orf2/CFAP410 & $21 \mathrm{q} 22.3$ & $\mathrm{AD}, \mathrm{RF}$ & 2.21 & Cytoskeletal organisation; cilia formation \\
\hline C9orf72 & $9 \mathrm{p} 21.2$ & $\mathrm{AD}$ & 3.34 & $\begin{array}{l}\text { Autophagy; intracellular trafficking; proteostasis; } \\
\text { nucleocytoplasmic transport }\end{array}$ \\
\hline CAPN14 & $2 \mathrm{p} 23.1$ & $\mathrm{RF}$ & 3.79 & Apoptosis; cytoskeletal dynamics \\
\hline$C C N F$ & $16 \mathrm{p} 13.3$ & $\mathrm{AD}$ & 4.23 & Proteostasis \\
\hline CHCHDIO & $22 \mathrm{q} 11.23$ & $\mathrm{AD}$ & 1.17 & Autophagy; neuroinflammation \\
\hline CHMP $2 B$ & $3 p 11.2$ & $\mathrm{AD}$ & 2.59 & Vesicular trafficking; proteostasis \\
\hline$C Y L D$ & $16 \mathrm{q} 12.1$ & $\mathrm{AD}$ & 8.5 & Deubiquitinase activity \\
\hline$D A O$ & $12 \mathrm{q} 24.11$ & $\mathrm{AD}$ & 1.69 & $\mathrm{D}$-serine regulation \\
\hline DCTNI & $2 \mathrm{p} 13.1$ & $\mathrm{AD}$ & 4.5 & Vesicular trafficking; proteostasis \\
\hline DDX20 & $1 \mathrm{p} 13.2$ & $\mathrm{RF}$ & 3.6 & Ribostasis \\
\hline DNAJC7 & $17 \mathrm{q} 21.2$ & $\mathrm{AD}$ & 1.81 & Proteostasis \\
\hline ELP3 & $8 \mathrm{p} 21.1$ & RF & 3.15 & Ribostasis; cytoskeletal integrity \\
\hline ERBB4 & $2 \mathrm{q} 34$ & $\mathrm{AD}$ & 12.1 & Cell signalling \\
\hline EWSRl & $22 \mathrm{q} 12.2$ & $\mathrm{AD}$ & 2.65 & Ribostasis \\
\hline FIG4 & $6 \mathrm{q} 21$ & $\mathrm{AD}$ & 3.01 & Vesicular trafficking \\
\hline FUS & $16 \mathrm{p} 11.2$ & $\mathrm{AD}$ & 5.12 & Ribostasis \\
\hline$G G N B P 2$ & $17 q 12$ & RF & 2.82 & Cell signalling \\
\hline GLE1 & $9 \mathrm{q} 34.11$ & AR & 3.32 & Ribostasis \\
\hline GLT8D1 & $3 \mathrm{p} 21.1$ & $\mathrm{AD}$ & 1.85 & Proteostasis \\
\hline$G P X 3$ & $5 q 33.1$ & $\mathrm{RF}$ & 1.6 & Oxidative stress \\
\hline$G R N$ & $17 \mathrm{q} 21.31$ & $\mathrm{AD}$ & 2.13 & Cell growth \\
\hline HNRNPAl & $12 \mathrm{q} 13.13$ & $\mathrm{AD}$ & 1.84 & Ribostasis \\
\hline HNRNPA2BI & $7 \mathrm{p} 15.2$ & $\mathrm{AD}$ & 3.66 & Ribostasis \\
\hline KIF5A & $12 \mathrm{q} 13.3$ & $\mathrm{AD}$ & 5.78 & Vesicular trafficking \\
\hline$M A P T$ & $17 \mathrm{q} 21.31$ & $\mathrm{AD}$ & 6.82 & Cytoskeletal organisation \\
\hline MATR3 & $5 \mathrm{q} 31.2$ & $\mathrm{AD}$ & 4.84 & Ribostasis \\
\hline$M O B P$ & $3 \mathrm{p} 22.1$ & RF & 1.34 & Structural constituent of myelin sheath \\
\hline $\mathrm{NEFH}$ & $22 \mathrm{q} 12.2$ & $\mathrm{AD}$ & 3.78 & Axonal transport \\
\hline$N E K I$ & $4 q 33$ & $\mathrm{AD}$ & 5.65 & DNA damage repair \\
\hline NIPAI & $15 \mathrm{q} 11.2$ & $\mathrm{RF}$ & 6.55 & Vesicular trafficking \\
\hline OPTN & $10 \mathrm{p} 13$ & $\mathrm{AD}, \mathrm{AR}$ & 3.52 & NfkB signal transduction; autophagy \\
\hline PFN1 & $17 \mathrm{p} 13.2$ & $\mathrm{AD}$ & 1.29 & Cytoskeletal organisation; axonal growth and transport \\
\hline$P R P H$ & $12 \mathrm{q} 13.12$ & $\mathrm{AD}$ & 1.8 & Cytoskeletal organisation \\
\hline SARMI & $17 \mathrm{q} 11.2$ & $\mathrm{RF}$ & 10.27 & Cell signalling \\
\hline SCFD1 & $14 \mathrm{q} 12$ & $\mathrm{RF}$ & 2.36 & Vesicular trafficking \\
\hline SETX & $9 \mathrm{q} 34.13$ & $\mathrm{AD}$ & 11.1 & Ribostasis \\
\hline SIGMARI & $9 \mathrm{p} 13.3$ & AR & 1.67 & Signal transduction amplification \\
\hline SMN1 & $5 q 13.2$ & $\mathrm{RF}$ & 1.55 & Ribostasis \\
\hline$S M N 2$ & $5 q 13.2$ & $\mathrm{RF}$ & 1.55 & Ribostasis \\
\hline$S O D I$ & $21 \mathrm{q} 22.11$ & $\mathrm{AR}, \mathrm{AD}$ & 0.97 & Oxidative stress; proteostasis \\
\hline SPAST & $2 \mathrm{p} 22.3$ & $\mathrm{AD}$ & 5.28 & Endocytosis \\
\hline SPG11 & $15 \mathrm{q} 14$ & AR & 7.77 & Cytoskeletal organisation; vesicular transport \\
\hline$S Q S T M 1$ & $5 q 35.3$ & $\mathrm{AD}$ & 2.84 & Autophagy; neuroinflammation \\
\hline SSI8L1 & $20 \mathrm{q} 13.33$ & $\mathrm{AD}$ & 4.55 & Ribostasis \\
\hline TAF15 & $17 \mathrm{q} 12$ & $\mathrm{AR}, \mathrm{AD}$ & 2.16 & Ribostasis \\
\hline$T A R D B P$ & $1 \mathrm{p} 36.22$ & $\mathrm{AD}$ & 5.37 & Ribostasis \\
\hline$T B K 1$ & $12 \mathrm{q} 14.2$ & $\mathrm{AD}$ & 3.02 & Autophagy, inflammation \\
\hline TIAl & $2 \mathrm{p} 13.3$ & $\mathrm{AD}$ & 4.63 & Ribostasis \\
\hline TNIPI & $5 \mathrm{q} 33.1$ & $\mathrm{RF}$ & 2.79 & $\mathrm{Nf \kappa B}$ signal transduction \\
\hline$T U B A 4 A$ & $2 \mathrm{q} 35$ & $\mathrm{AD}$ & 2.05 & Cytoskeletal organisation; axonal transport \\
\hline$U B Q L N 2$ & $\mathrm{Xp} 11.21$ & $\mathrm{XD}$ & 4.23 & Proteostasis \\
\hline UNC13A & 19p13.11 & $\mathrm{RF}$ & 9.84 & Neurotransmitter release regulation \\
\hline$V A P B$ & $20 \mathrm{q} 13.32$ & $\mathrm{AD}$ & 7.94 & Proteostasis \\
\hline$V C P$ & $9 \mathrm{p} 13.3$ & $\mathrm{AD}$ & 3.75 & Proteostasis \\
\hline
\end{tabular}


Table 2 Baseline characteristics of ALS patients and controls.

\begin{tabular}{|c|c|c|}
\hline & $\begin{array}{l}\text { ALS } \\
(n=24)\end{array}$ & $\begin{array}{l}\text { Controls } \\
(n=13)\end{array}$ \\
\hline \multicolumn{3}{|l|}{ Sex } \\
\hline Male, \% (n) & $66.7(16)$ & $46.2(6)$ \\
\hline Female, \% (n) & $33.3(8)$ & $53.8(7)$ \\
\hline \multicolumn{3}{|l|}{ Type } \\
\hline Familial, \% (n) & $12.5(3)$ & - \\
\hline Sporadic, \% (n) & $87.5(21)$ & - \\
\hline \multicolumn{3}{|l|}{ Age at onset } \\
\hline Mean year \pm SD (range) & $\begin{array}{l}59.3 \pm 13.2 \\
(27-80)\end{array}$ & - \\
\hline \multicolumn{3}{|l|}{ Age at recruitment } \\
\hline Mean year \pm SD (range) & $\begin{array}{l}63.5 \pm 11.6 \\
(30-82)\end{array}$ & $\begin{array}{l}71.2 \pm 10.9 \\
(52-90)\end{array}$ \\
\hline $\begin{array}{l}\text { ALSFRS-R score, mean } \pm \text { SD } \\
\text { (range) }\end{array}$ & $\begin{array}{l}25.6 \pm 11.1 \\
(11.5-44)\end{array}$ & $\begin{array}{l}47.9 \pm 0.3 \\
(47-48)\end{array}$ \\
\hline \multicolumn{3}{|l|}{ Site of onset } \\
\hline Spinal, \% (n) & $70.8(17)$ & - \\
\hline Bulbar, \% (n) & $25(6)$ & - \\
\hline Both, \% (n) & $4.2(1)$ & \\
\hline $\begin{array}{l}\text { Survival, mean years } \pm \text { SD } \\
\text { (range) }\end{array}$ & $5.5 \pm 5.1(2-20)$ & - \\
\hline Deceased, \% (n) & $62.5(15)$ & - \\
\hline \multicolumn{3}{|l|}{ Cognitive status } \\
\hline Normal, \% (n) & $95.8(23)$ & $100(13)$ \\
\hline Impaired, \% (n) & $4.2(1)$ & $0(0)$ \\
\hline \multicolumn{3}{|l|}{ Environmental risk factors } \\
\hline Heavy smoking, \% (n) & $33.3(8)$ & $23.1(3)$ \\
\hline Strenuous activity, \% (n) & $54.2(13)$ & $23.1(3)$ \\
\hline $\begin{array}{l}\text { Excessive alcohol } \\
\text { consumption, \% (n) }\end{array}$ & $8.3(2)$ & $7.8(1)$ \\
\hline \multicolumn{3}{|l|}{ CK levels at recruitment, IU/L ${ }^{a}$} \\
\hline Mean in males $\pm \mathrm{SD}$ (range) & $\begin{array}{l}311.2 \pm 259.7 \\
(15-863)\end{array}$ & - \\
\hline $\begin{array}{l}\text { Mean in females } \pm \text { SD } \\
\text { (range) }\end{array}$ & $\begin{array}{l}180.8 \pm 117.5 \\
(38-336)\end{array}$ & - \\
\hline
\end{tabular}

ALSFRS-R Amyotrophic Lateral Sclerosis Functional Rating ScaleRevised, $C K$ creatine kinase.

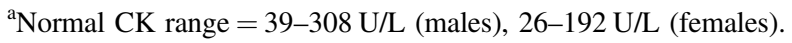

alive at the prevalence date $\left(31^{\text {st }}\right.$ December 2018), corresponding to a crude prevalence of $3.44 / 100,000$ (95\% CI 2.01-5.52). Similarly, the prevalence in males $(5.16,95 \%$ CI 2.74-8.83) was higher than that in females $(1.66,95 \%$ CI 0.45-4.24), leading to a male-to-female prevalence ratio of 3.11:1. There was no difference in the mean age of onset and site of onset between prevalent and incident patients.

\section{Genetic ancestry}

PCA analysis of the Maltese case-control cohort showed that cases and controls were within 3 standard deviations of

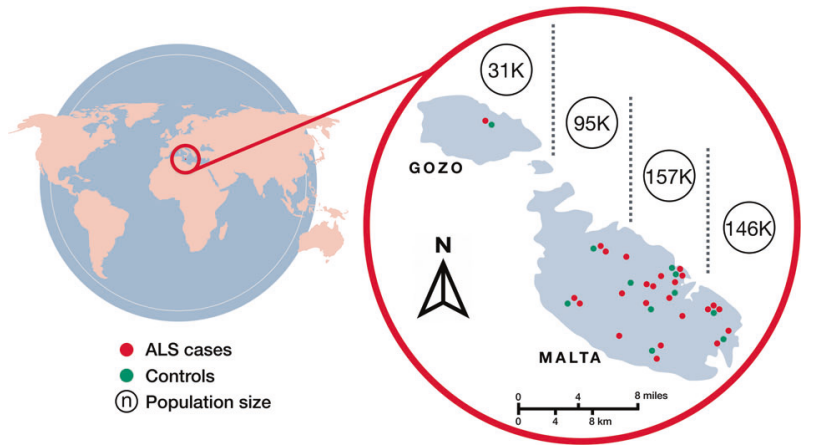

Fig. 1 Geographical distribution of ALS cases and controls for individuals born on the Maltese islands. Population size of the four regional divisions (separated by dotted lines) is based on NSO data in 2017.

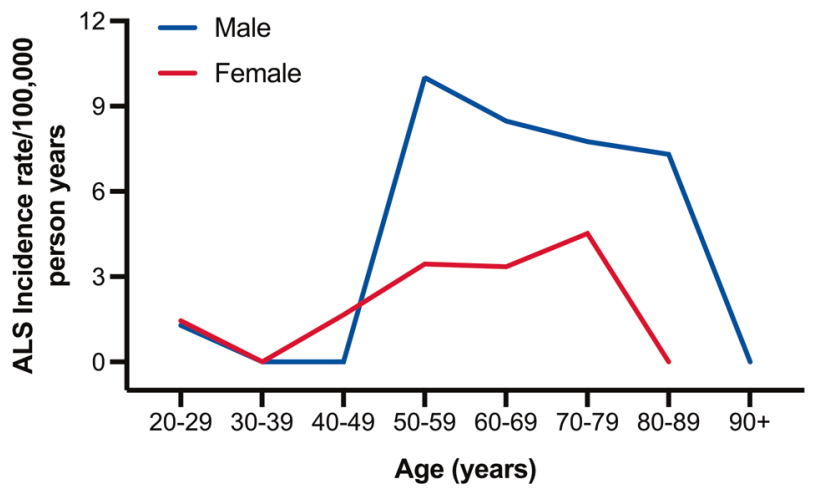

Fig. 2 Change in incidence rate of ALS with age in Malta. Incidence rate increases with age and was higher for males compared to females across all age groups after 49 years. Peaks occur in the 50-59 age group for men and in the 70-79 age group for women.

the mean for the combined samples along principal components (PC) 1-4, hence ensuring adequate genetic matching. Mapping the Maltese ALS patient and control samples to the reference PCA coordinates for samples from the Human Genome Diversity Panel (HGDP) shows overlap with the portion of the Middle-Eastern cluster that neighbours the European cluster (Fig. 3). A genetic affinity with Middle East populations is also apparent in Sicilians $[34,35]$, further supporting a common genetic ancestry for populations inhabiting the Mediterranean islands of Malta and Sicily.

\section{Repeat expansions in C9orf72, ATXN2 and NIPA1 genes}

Despite studies which show that $C 9$ orf72 is the major gene that is mutated in the European ALS population $[8,36,37]$, we did not identify pathogenic hexanucleotide (GGGGCC) repeat expansions ( $\geq 24)$ in $C 9$ orf72 in either fALS or sALS cases (Fig. 4). The expansion repeat size ranged from 2 to 10 in controls and from 2 to 13 in ALS 

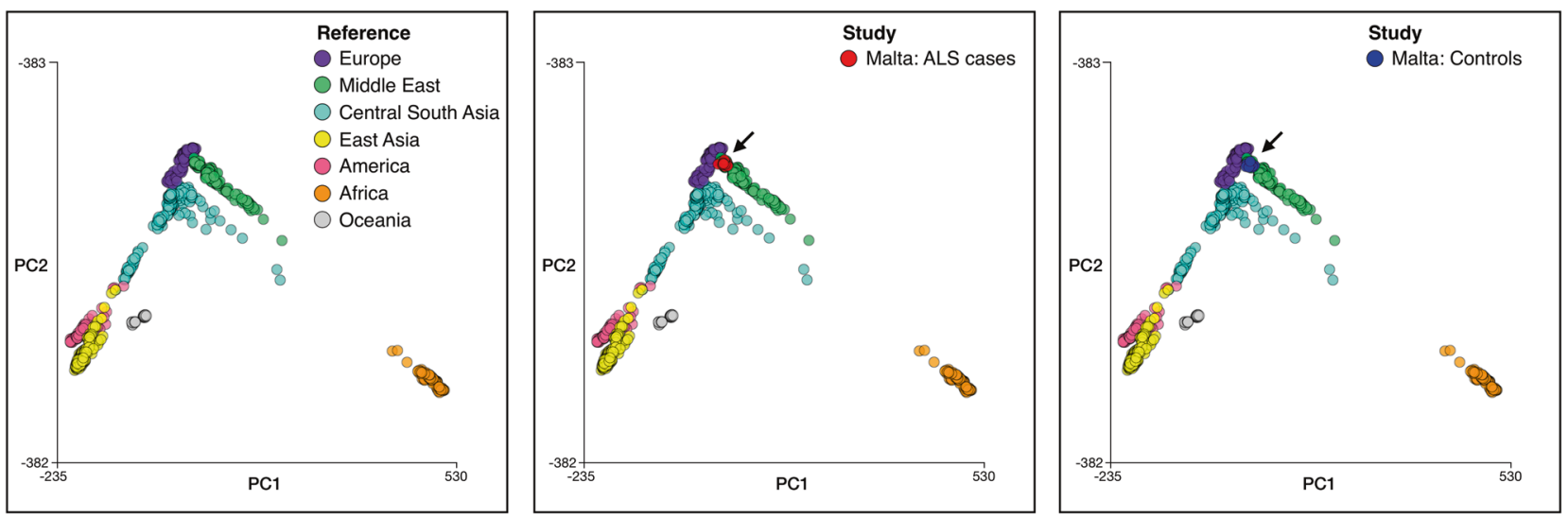

Fig. 3 Ancestry of Maltese ALS cases and controls compared to the HGDP reference panel. Left panel, Reference PCA coordinates for samples from the HGDP reference panel. Middle panel, Maltese ALS cases mapped to the reference PCA coordinates. Right panel, Maltese controls mapped to the reference PCA coordinates.

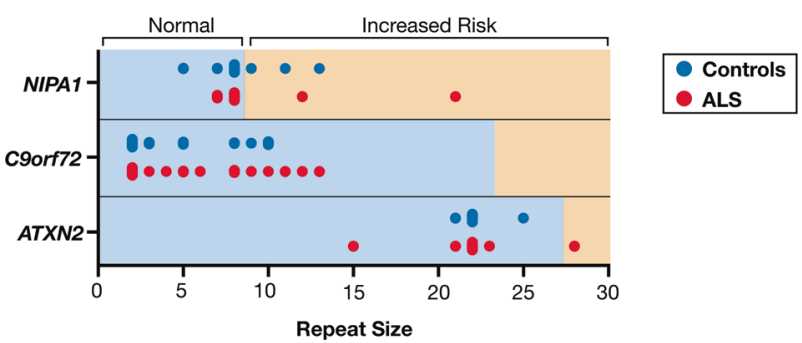

Fig. 4 Expansion repeat size in ALS cases and controls for NIPA1, C9orf72 and ATXN2 genes. Scatter plot showing distribution and frequency of repeat sizes, indicated by circles.

patients. Consistent with previous studies [36, 37], a repeat length of 2 was the most predominant in either group (42.3\% in controls and $52.2 \%$ in ALS cases). In addition to C9orf72, repeat expansions in other genes including ATXN2 and NIPA1 have been associated with increased risk of ALS [11,38]. We identified one male patient with fALS that possessed ATXN2 ALS-associated trinucleotide repeat expansions (28 repeats in length) in the homozygous state (Fig. 4). At the age of 67 years, this patient first experienced bilateral leg weakness that progressed. He subsequently developed dysarthria and succumbed to the disease within 2 years of disease onset. This patient was also the only one in our cohort that showed signs of cognitive impairment. Family history was notable for a deceased sister who had ALS with early onset in her late $30 \mathrm{~s}$, and a deceased mother who had dementia (DNA samples were not available for study). The pedigree is shown in Supplementary Fig. S1. The maximum ATXN2 repeat size observed in healthy controls was 25 , encountered in the heterozygous state, in one subject. All remaining ALS patients and controls had repeat lengths $\leq 23$. As was reported previously $[11,39]$, a repeat length of 22 , detected mostly in the homozygous state, was the most abundant ATXN2 allele (88.5\% in controls and $84.8 \%$ in ALS patients). Considering NIPAl, we found one male patient with sALS who had an expanded [21] GCG repeat motif in the heterozygous state. The patient had a late age of onset (73 years), experiencing bilateral weakness first in the lower limbs and then in the upper limbs. Survival was shorter $(<2.5$ years $)$ compared with the median survival (3.5 years) in our ALS cohort. In controls and in the remaining ALS cases, repeat length was variable ranging from 5 to 13 . Similar to previous findings [38, 40], the most frequent alleles consisted of either 7 or 8 repeats, with respective allele frequencies being $26.1 \%$ and $67.4 \%$ in ALS patients, and $7.7 \%$ and $73.1 \%$ in controls.

\section{Genetic variants in known ALS-associated genes}

Interestingly, the Maltese ALS patient cohort was found to be negative for non-synonymous or splice-site altering SNVs in the SOD1, TARDBP or FUS genes, which are the most commonly mutated ALS genes, in that order, following C9orf72 [8]. After examining 58 ALS-associated genes in our patient and control cohort, we identified 35 rare (European MAF $\leq 0.01$ ) coding variants that were present in Maltese ALS patients and absent in controls (Table 3). Three SNVs in DDX20, EWSR1 or GLE1 were not found in the dbSNP (v141) database. The NM_001003722.1: c.2078C >T; p.(Ser693Phe) variant in GLE1 was however reported in a recent study as a founder mutation in Maltese that on homozygosis induces a motor dysfunction syndrome that presents at childhood [21]. Variants predicted to be damaging by both MetaSVM and MetaLR were detected in ALS2, DAO, DCTN1, ERBB4, SCFD1 and SPG11 (Table 3). All were detected in patients with sALS. The NM_001917.4:c.250G >A; p.(Ala84Thr) variant in DAO was detected in two patients, whereas one female patient possessed deleterious variants in more than one gene (DAO and DCTN1). 


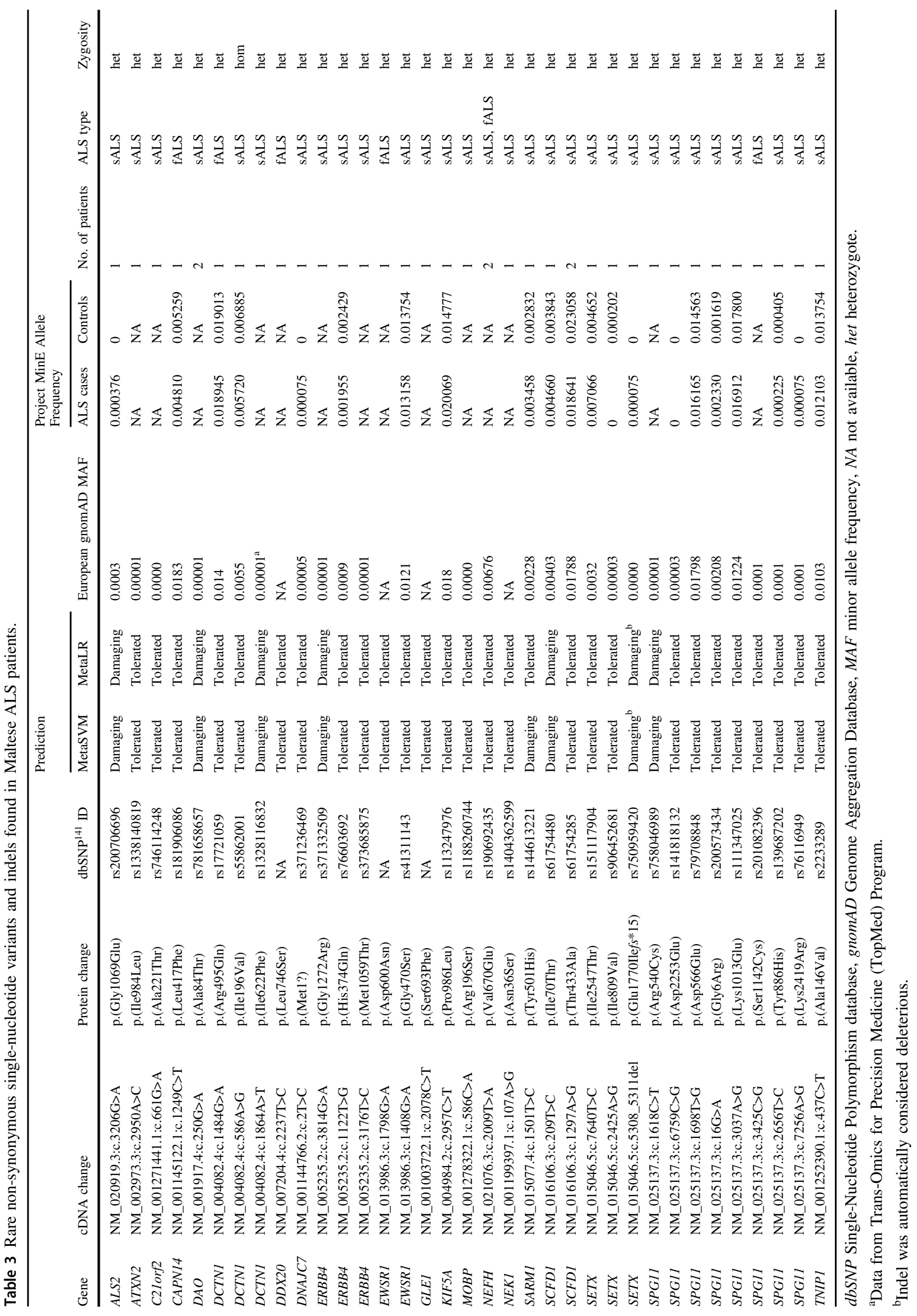


Analysis of indels allowed us to identify a rare deletion in SETX, detected in the heterozygous state in a sALS case (Table 3). This patient presented with upper limb weakness at the age of 70 . One year later, on follow-up, weakness spread to the lower limbs. The deletion is predicted to result in a frameshift, consequently producing a truncated SETX protein lacking the helicase domain. It is noteworthy that the damaging $A L S 2, S C F D 1$, and SETX variants detected in Maltese sALS patients were found to have higher allele frequencies in ALS patients within the Project MinE casecontrol dataset [27], thereby underscoring their probable pathogenicity (Table 3). Rare SNVs or indels that were unique to controls or that were shared by ALS patients and controls are listed in Supplementary Table S1. One SNVs in FIG4 was not found in the dbSNP (v141) database. No homozygous stretches were overrepresented in sALS patients compared to controls (Supplementary Fig. S2). To estimate the genetic risk for ALS in the Maltese population, we determined that the percentage of sALS cases caused by rare and potentially deleterious variants (absent in controls) in at least one ALS-associated gene was $40 \%$ (8/20 patients). Two fALS cases did not carry any mutations in known ALS genes or risk loci, hence, warranting further studies to elucidate novel genes that cause ALS.

\section{Discussion}

In our work, we investigated the characteristics of Maltese ALS patients, described their genetic profile, and determined the incidence and prevalence of ALS on the Maltese islands. It is interesting that the population-specific aspects of our ALS cases overlap those reported for other neighbouring European populations, especially those in the Mediterranean including the island of Sicily [41] and the southern region of Puglia $[42,43]$ in Italy, Tunisia [44] and Cyprus [45]. Although the male preponderance in ALS is virtually universal [46, 47], it is noteworthy that in these specific populations as well as in Malta, age at disease onset is higher in males than in females. This is in contrast to northern populations of the Mediterranean basin including Catalonia in Spain [48], and the regions of Emilia Romagna [49], Liguria [50] or Friuli-Venezia-Giulia [51] in Italy. Incidence and prevalence of ALS in Malta is similar to the European median [3].

We report a higher percentage $(12.5 \%)$ of fALS cases in Malta, close to that reported for the northern Italian population of Liguria (10\%) [50] but nearly half that reported for the island of Sardinia (26.7\%) [52]. Nonetheless, similar to previous studies [53], relaxing the stringent criteria by including neurological conditions in kindreds that have a genetic overlap with ALS [54], can increase the fALS percentage in Malta by threefold $(37.5 \%)$. In agreement, considering the Maltese sALS subset, we showed that, compared to other European populations [10] or populations of European ancestry [9], a higher proportion of seemly sALS patients are probably genetically determined.

Intriguingly, rare deleterious variants in the major ALS genes, including C9orf72, SOD1, TARDBP and FUS, were absent in Maltese ALS patients. This finding confirms the presence of a North-South gradient in the frequency of mutations within these genes across Europe. Hence, C9orf72 or SOD1 mutations in fALS are highest in northern European countries like Belgium and Finland, whereas a relatively low frequency is recorded in the south of Europe including Spain and mainland Italy [8]. A similar situation can be observed for TARDBP and FUS [8]. Our study thus underscores the marked differences that exists between ethnic groups and geographical regions with respect to the genes that are commonly implicated in ALS.

Maltese ALS patients nevertheless possessed deleterious alleles in 'minor' ALS genes including $A L S 2, A T X N 2$, DAO, DCTN1, ERBB4, NIPA1, SETX, SCFDI and SPG11. $A L S 2$ and $S P G 11$ have been associated with juvenile-onset ALS only under a recessive disease model [55-58]. In this context, since we observed variants in the ALS2 and SPG11 genes solely in heterozygous configurations and in patients which had adult-onset ALS, it is likely that these alleles were not disease causing in the patients that possessed them. However, considering that ALS has an oligogenic basis [59], a modifying or additive effect cannot be excluded. The same can be said for $S C F D 1$, which has only been recently identified as a risk locus [13], and for which we report a damaging variant in an ALS patient with a young age of onset (27 years) and whose disease progression is exceptionally slow.

ATXN2, DAO, DCTN1, ERBB4, NIPA1 and SETX have all been previously associated with ALS having an autosomal dominant mode of inheritance [11, 38, 40, 60-63]. Damaging alleles discovered in our patient cohort, which specifically target these genes, are most probably causative. It is interesting to note that the ERBB4 c. $3814 \mathrm{G}>\mathrm{A}$; p. (Gly1272Arg) variant reported in this study is extremely close to the one reported in a Japanese sALS individual [c.3823C $>\mathrm{T}$; p.(Arg1275Trp)], both of which are located in the C-terminal domain of the protein, close to multiple phosphorylation sites, which mediate downstream signalling pathways [61]. Although SETX variants have been initially discovered in juvenile-onset ALS patients [62], reports have since described damaging alleles in patients with adult-onset ALS [10, 64]. This is in line with our study, hence, the Maltese ALS patient possessing a SETX deletion had a late age of onset similar to the one reported in a previous case study [64].

Our findings have important implications. Incidence and prevalence of ALS in Malta as well as patient population 
aspects overlap those of neighbouring countries. However, supported by genetic ancestry results, the genetic architecture of ALS in Malta appears to be different from the European average underscoring genetic isolation imposed by geography. This combined with the lack of an identified genetic factor in two-thirds of Maltese fALS cases, encourages further studies aimed at discovering novel ALS genes. Our 'preliminary' data excludes the possibility that these patients have deleterious variants in a set of genes associated with other motor neuron disorders including hereditary ataxias, and hereditary motor and sensory neuropathies (data not shown). Finally, variants described in this work should spur the generation of animal models to confirm causation and better understand disease mechanisms [65]. This is imperative especially for 'minor' ALS genes, given that they are relatively less studied than 'major' genes, but which are nonetheless consequential in specific populations.

Acknowledgements The authors are grateful to Prof. Richard Muscat, Wilfred Kenely and Dr. Graziella Zahra for their support of this work. Thanks also goes to Matthew Camilleri for unwavering technical and administrative support. We remain indebted to all participants of this study.

Funding This work was supported by the University of Malta Research Excellence Fund to RJC, and the Malta Council for Science \& Technology Internationalisation Partnership Award to RJC. $\mathrm{RB}$ was supported by an EMBO short-term fellowship and by a Bjorn Formosa Scholarship for Advanced Research into ALS/MND funded by the non-profit organisation, ALS Malta Foundation, facilitated by the Research Trust (RIDT) of the University of Malta. ML was supported by an Endeavour Scholarship (Malta), partfinanced by the EU-European Social Fund under Operational Programme II-Cohesion Policy 2014-2020, "Investing in human capital to create more opportunities and promote the well-being of society".

\section{Compliance with ethical standards}

Conflict of interest The authors declare that they have no conflict of interest.

Publisher's note Springer Nature remains neutral with regard to jurisdictional claims in published maps and institutional affiliations.

Open Access This article is licensed under a Creative Commons Attribution 4.0 International License, which permits use, sharing, adaptation, distribution and reproduction in any medium or format, as long as you give appropriate credit to the original author(s) and the source, provide a link to the Creative Commons license, and indicate if changes were made. The images or other third party material in this article are included in the article's Creative Commons license, unless indicated otherwise in a credit line to the material. If material is not included in the article's Creative Commons license and your intended use is not permitted by statutory regulation or exceeds the permitted use, you will need to obtain permission directly from the copyright holder. To view a copy of this license, visit http://creativecommons. org/licenses/by/4.0/.

\section{References}

1. Brown RH, Al-Chalabi A. Amyotrophic lateral sclerosis. N Engl J Med. 2017;377:162-72.

2. van Es MA, Hardiman O, Chio A, Al-Chalabi A, Pasterkamp RJ, Veldink JH, et al. Amyotrophic lateral sclerosis. Lancet. 2017; 390:2084-98.

3. Chio A, Logroscino G, Traynor BJ, Collins J, Simeone JC, Goldstein LA, et al. Global epidemiology of amyotrophic lateral sclerosis: a systematic review of the published literature. Neuroepidemiology. 2013;41:118-30.

4. Byrne S, Walsh C, Lynch C, Bede P, Elamin M, Kenna K, et al. Rate of familial amyotrophic lateral sclerosis: a systematic review and meta-analysis. J Neurol Neurosurg Psychiatry. 2011;82: 623-7.

5. Al-Chalabi A, Fang F, Hanby MF, Leigh PN, Shaw CE, Ye W, et al. An estimate of amyotrophic lateral sclerosis heritability using twin data. J Neurol Neurosurg Psychiatry. 2010;81:1324-6.

6. Ryan M, Heverin M, McLaughlin RL, Hardiman O. Lifetime risk and heritability of amyotrophic lateral sclerosis. JAMA Neurol. 2019;76:1367-74.

7. Trabjerg BB, Garton FC, van Rheenen W, Fang F, Henderson RD, Mortensen PB, et al. ALS in Danish registries: heritability and links to psychiatric and cardiovascular disorders. Neurol Genet. 2020;6: e398.

8. Zou ZY, Zhou ZR, Che CH, Liu CY, He RL, Huang HP. Genetic epidemiology of amyotrophic lateral sclerosis: a systematic review and meta-analysis. J Neurol Neurosurg Psychiatry. 2017;88: 540-9.

9. Gibson SB, Downie JM, Tsetsou S, Feusier JE, Figueroa KP, Bromberg MB, et al. The evolving genetic risk for sporadic ALS. Neurology. 2017;89:226-33.

10. Kenna KP, McLaughlin RL, Byrne S, Elamin M, Heverin M, Kenny EM, et al. Delineating the genetic heterogeneity of ALS using targeted high-throughput sequencing. J Med Genet. 2013; 50:776-83.

11. Elden AC, Kim HJ, Hart MP, Chen-Plotkin AS, Johnson BS, Fang $X$, et al. Ataxin-2 intermediate-length polyglutamine expansions are associated with increased risk for ALS. Nature. 2010;466:1069-75.

12. van Es MA, Veldink JH, Saris CG, Blauw HM, van Vught PW, Birve A, et al. Genome-wide association study identifies 19p13.3 (UNC13A) and 9p21.2 as susceptibility loci for sporadic amyotrophic lateral sclerosis. Nat Genet. 2009;41:1083-7.

13. van Rheenen W, Shatunov A, Dekker AM, McLaughlin RL, Diekstra FP, Pulit SL, et al. Genome-wide association analyses identify new risk variants and the genetic architecture of amyotrophic lateral sclerosis. Nat Genet. 2016;48:1043-8.

14. Taylor JP, Brown RH Jr., Cleveland DW. Decoding ALS: from genes to mechanism. Nature. 2016;539:197-206.

15. Ly CV, Miller TM. Emerging antisense oligonucleotide and viral therapies for amyotrophic lateral sclerosis. Curr Opin Neurol. 2018:31:648-54.

16. Arcos-Burgos M, Muenke M. Genetics of population isolates. Clin Genet. 2002;61:233-47.

17. Caruana J. Population genetics of Western Mediterranean Islands-Malta: a case study. Manchester: University of Manchester; 2012.

18. Capelli C, Redhead N, Romano V, Cali F, Lefranc G, Delague V, et al. Population structure in the Mediterranean basin: a Y chromosome perspective. Ann Hum Genet. 2006;70:207-25.

19. Cassar M, Farrugia C, Vidal C. Allele frequencies of 14 STR loci in the population of Malta. Leg Med. 2008;10:153-6.

20. Borg J, Papadopoulos P, Georgitsi M, Gutierrez L, Grech G, Fanis $\mathrm{P}$, et al. Haploinsufficiency for the erythroid transcription 
factor KLF1 causes hereditary persistence of fetal hemoglobin. Nat Genet. 2010;42:801-5.

21. Said E, Chong JX, Hempel M, Denecke J, Soler P, Strom T, et al. Survival beyond the perinatal period expands the phenotypes caused by mutations in GLE1. Am J Med Genet A. 2017;173:3098-103.

22. Brooks BR, Miller RG, Swash M, Munsat TL. World Federation of Neurology Research Group on Motor Neuron D. El Escorial revisited: revised criteria for the diagnosis of amyotrophic lateral sclerosis. Amyotroph Lateral Scler Other Mot Neuron Disord. 2000;1:293-9.

23. Ludolph A, Drory V, Hardiman O, Nakano I, Ravits J, Robberecht W, et al. A revision of the El Escorial criteria - 2015. Amyotroph Lateral Scler Frontotemporal Degener. 2015;16:291-2.

24. Dolzhenko E, van Vugt J, Shaw RJ, Bekritsky MA, van Blitterswijk M, Narzisi G, et al. Detection of long repeat expansions from PCR-free whole-genome sequence data. Genome Res. 2017;27:1895-903.

25. Seelow D, Schuelke M. HomozygosityMapper2012-bridging the gap between homozygosity mapping and deep sequencing. Nucleic Acids Res. 2012;40:W516-20.

26. Nicolas A, Kenna KP, Renton AE, Ticozzi N, Faghri F, Chia R, et al. Genome-wide analyses identify KIF5A as a novel ALS gene. Neuron. 2018;97:1268-83 e6.

27. van der Spek RAA, van Rheenen W, Pulit SL, Kenna KP, van den Berg LH, Veldink JH, et al. The project MinE databrowser: bringing large-scale whole-genome sequencing in ALS to researchers and the public. Amyotroph Lateral Scler Frontotemporal Degener. 2019;20:432-40.

28. Dong C, Wei P, Jian X, Gibbs R, Boerwinkle E, Wang K, et al. Comparison and integration of deleteriousness prediction methods for nonsynonymous SNVs in whole exome sequencing studies. Hum Mol Genet. 2015;24:2125-37.

29. Byrne S, Heverin M, Elamin M, Bede P, Lynch C, Kenna K, et al. Aggregation of neurologic and neuropsychiatric disease in amyotrophic lateral sclerosis kindreds: a population-based casecontrol cohort study of familial and sporadic amyotrophic lateral sclerosis. Ann Neurol. 2013;74:699-708.

30. O'Brien M, Burke T, Heverin M, Vajda A, McLaughlin R, Gibbons $\mathrm{J}$, et al. Clustering of neuropsychiatric disease in first-degree and second-degree relatives of patients with amyotrophic lateral sclerosis. JAMA Neurol. 2017;74:1425-30.

31. Longinetti E, Mariosa D, Larsson $\mathrm{H}, \mathrm{Ye} \mathrm{W}$, Ingre $\mathrm{C}$, Almqvist $\mathrm{C}$, et al. Neurodegenerative and psychiatric diseases among families with amyotrophic lateral sclerosis. Neurology 2017;89:578-85.

32. Peters S, Visser AE, D'Ovidio F, Vlaanderen J, Portengen L, Beghi E, et al. Effect modification of the association between total cigarette smoking and ALS risk by intensity, duration and timesince-quitting: Euro-MOTOR. J Neurol Neurosurg Psychiatry. 2020;91:33-9.

33. Visser AE, Rooney JPK, D’Ovidio F, Westeneng HJ, Vermeulen $\mathrm{RCH}$, Beghi E, et al. Multicentre, cross-cultural, populationbased, case-control study of physical activity as risk factor for amyotrophic lateral sclerosis. J Neurol Neurosurg Psychiatry. 2018;89:797-803.

34. Di Gaetano C, Voglino F, Guarrera S, Fiorito G, Rosa F, Di Blasio $\mathrm{AM}$, et al. An overview of the genetic structure within the Italian population from genome-wide data. PLoS ONE. 2012;7:e43759.

35. Sarno S, Boattini A, Pagani L, Sazzini M, De Fanti S, Quagliariello A, et al. Ancient and recent admixture layers in Sicily and Southern Italy trace multiple migration routes along the Mediterranean. Sci Rep. 2017;7:1984.

36. Renton AE, Majounie E, Waite A, Simon-Sanchez J, Rollinson S, Gibbs JR, et al. A hexanucleotide repeat expansion in C9ORF72 is the cause of chromosome 9p21-linked ALS-FTD. Neuron. 2011;72:257-68.
37. Smith BN, Newhouse S, Shatunov A, Vance C, Topp S, Johnson $\mathrm{L}$, et al. The C9ORF72 expansion mutation is a common cause of ALS+/-FTD in Europe and has a single founder. Eur $\mathbf{J}$ Hum Genet. 2013;21:102-8.

38. Blauw HM, van Rheenen W, Koppers M, Van Damme P, Waibel $\mathrm{S}$, Lemmens $\mathrm{R}$, et al. NIPA1 polyalanine repeat expansions are associated with amyotrophic lateral sclerosis. Hum Mol Genet. 2012;21:2497-502.

39. Van Damme P, Veldink JH, van Blitterswijk M, Corveleyn A, van Vught PW, Thijs V, et al. Expanded ATXN2 CAG repeat size in ALS identifies genetic overlap between ALS and SCA2. Neurology. 2011;76:2066-72.

40. Tazelaar GHP, Dekker AM, van Vugt J, van der Spek RA, Westeneng HJ, Kool L, et al. Association of NIPA1 repeat expansions with amyotrophic lateral sclerosis in a large international cohort. Neurobiol Aging. 2019;74:234 e9-15.

41. Ragonese P, Cellura E, Aridon P, D'Amelio M, Spataro R, Taiello $\mathrm{AC}$, et al. Incidence of amyotrophic lateral sclerosis in Sicily: a population based study. Amyotroph Lateral Scler. 2012;13:284-7.

42. Logroscino G, Beghi E, Zoccolella S, Palagano R, Fraddosio A, Simone IL, et al. Incidence of amyotrophic lateral sclerosis in southern Italy: a population based study. J Neurol Neurosurg Psychiatry. 2005;76:1094-8.

43. Zoccolella S, Beghi E, Palagano G, Fraddosio A, Samarelli V, Lamberti P, et al. Signs and symptoms at diagnosis of amyotrophic lateral sclerosis: a population-based study in southern Italy. Eur J Neurol. 2006;13:789-92.

44. Kacem I, Sghaier I, Bougatef S, Nasri A, Gargouri A, AjroudDriss $\mathrm{S}$, et al. Epidemiological and clinical features of amyotrophic lateral sclerosis in a Tunisian cohort. Amyotroph Lateral Scler Frontotemporal Degener. 2020;21:131-9.

45. Demetriou CA, Hadjivasiliou PM, Kleopa KA, Christou YP, Leonidou E, Kyriakides T, et al. Epidemiology of amyotrophic lateral sclerosis in the Republic of Cyprus: A 25-year retrospective study. Neuroepidemiology. 2017;48:79-85.

46. Logroscino G, Traynor BJ, Hardiman O, Chio A, Mitchell D, Swingler RJ, et al. Incidence of amyotrophic lateral sclerosis in Europe. J Neurol Neurosurg Psychiatry. 2010;81:385-90.

47. Marin B, Boumediene F, Logroscino G, Couratier P, Babron MC, Leutenegger $\mathrm{AL}$, et al. Variation in worldwide incidence of amyotrophic lateral sclerosis: a meta-analysis. Int J Epidemiol. 2017;46:57-74.

48. Pradas J, Puig T, Rojas-Garcia R, Viguera ML, Gich I, Logroscino $\mathrm{G}$, et al. Amyotrophic lateral sclerosis in Catalonia: a population based study. Amyotroph Lateral Scler Frontotemporal Degener. 2013;14:278-83.

49. Mandrioli J, Biguzzi S, Guidi C, Venturini E, Sette E, Terlizzi E, et al. Epidemiology of amyotrophic lateral sclerosis in Emilia Romagna Region (Italy): a population based study. Amyotroph Lateral Scler Frontotemporal Degener. 2014;15:262-8.

50. Scialo C, Novi G, Bandettini di Poggio M, Canosa A, Sormani MP, Mandich P. et al. Clinical epidemiology of amyotrophic lateral sclerosis in Liguria, Italy: an update of LIGALS register. Amyotroph Lateral Scler Frontotemporal Degener. 2016;17:535-42.

51. Palese F, Sartori A, Verriello L, Ros S, Passadore P, Manganotti $\mathrm{P}$, et al. Epidemiology of amyotrophic lateral sclerosis in FriuliVenezia Giulia, North-Eastern Italy, 2002-2014: a retrospective population-based study. Amyotroph Lateral Scler Frontotemporal Degener. 2019;20:90-9.

52. Borghero G, Pugliatti M, Marrosu F, Marrosu MG, Murru MR, Floris G, et al. Genetic architecture of ALS in Sardinia. Neurobiol Aging. 2014;35:2882 e7-12.

53. Ryan M, Heverin M, Doherty MA, Davis N, Corr EM, Vajda A, et al. Determining the incidence of familiality in ALS: A study of 
temporal trends in Ireland from 1994 to 2016. Neurol Genet. 2018;4:e239.

54. McLaughlin RL, Schijven D, van Rheenen W, van Eijk KR, O'Brien M, Kahn RS, et al. Genetic correlation between amyotrophic lateral sclerosis and schizophrenia. Nat Commun. 2017; 8:14774.

55. Hadano S, Hand CK, Osuga H, Yanagisawa Y, Otomo A, Devon RS, et al. A gene encoding a putative GTPase regulator is mutated in familial amyotrophic lateral sclerosis 2. Nat Genet. 2001;29:166-73.

56. Hentati A, Bejaoui K, Pericak-Vance MA, Hentati F, Speer MC, Hung WY, et al. Linkage of recessive familial amyotrophic lateral sclerosis to chromosome 2q33-q35. Nat Genet. 1994;7:425-8.

57. Daoud H, Zhou S, Noreau A, Sabbagh M, Belzil V, DionneLaporte A, et al. Exome sequencing reveals SPG11 mutations causing juvenile ALS. Neurobiol Aging. 2012;33:839 e5-9.

58. Orlacchio A, Babalini C, Borreca A, Patrono C, Massa R, Basaran $\mathrm{S}$, et al. SPATACSIN mutations cause autosomal recessive juvenile amyotrophic lateral sclerosis. Brain. 2010;133:591-8.

59. van Blitterswijk M, van Es MA, Hennekam EA, Dooijes D, van Rheenen W, Medic J, et al. Evidence for an oligogenic basis of amyotrophic lateral sclerosis. Hum Mol Genet. 2012;21:3776-84.
60. Mitchell J, Paul P, Chen HJ, Morris A, Payling M, Falchi M, et al. Familial amyotrophic lateral sclerosis is associated with a mutation in D-amino acid oxidase. Proc Natl Acad Sci USA. 2010; 107:7556-61.

61. Takahashi Y, Fukuda Y, Yoshimura J, Toyoda A, Kurppa K, Moritoyo H, et al. ERBB4 mutations that disrupt the neuregulinErbB4 pathway cause amyotrophic lateral sclerosis type 19. Am J Hum Genet. 2013;93:900-5.

62. Chen YZ, Bennett CL, Huynh HM, Blair IP, Puls I, Irobi J, et al. DNA/RNA helicase gene mutations in a form of juvenile amyotrophic lateral sclerosis (ALS4). Am J Hum Genet. 2004;74:1128-35.

63. Munch C, Sedlmeier R, Meyer T, Homberg V, Sperfeld AD, Kurt A, et al. Point mutations of the p150 subunit of dynactin (DCTN1) gene in ALS. Neurology. 2004;63:724-6.

64. Tripolszki K, Torok D, Goudenege D, Farkas K, Sulak A, Torok $\mathrm{N}$, et al. High-throughput sequencing revealed a novel SETX mutation in a Hungarian patient with amyotrophic lateral sclerosis. Brain Behav. 2017;7:e0669.

65. Aquilina B, Cauchi RJ. Modelling motor neuron disease in fruit flies: lessons from spinal muscular atrophy. J Neurosci Methods. 2018;310:3-11. 